International Journal of Automotive and Mechanical Engineering (IJAME)

ISSN: 2229-8649 (Print); ISSN: 2180-1606 (Online); Volume 6, pp. 755-767 July-December 2012

(C) Universiti Malaysia Pahang

DOI: http://dx.doi.org/10.15282/ijame.6.2012.7.0061

\title{
ANALYSIS OF LAMINAR FORCED CONVECTION OF AIR FOR CROSSFLOW OVER TWO STAGGERED FLAT TUBES
}

\author{
Tahseen A. Tahseen ${ }^{1}$, M. Ishak ${ }^{1}$ and M. M. Rahman ${ }^{1,2}$ \\ ${ }^{\mathbf{1}}$ Faculty of Mechanical Engineering, University Malaysia Pahang \\ 26600 Pekan, Pahang, Malaysia \\ Phone : +609-424-2246; Fax : +609-424-2202 \\ Email: mahadzir@ump.edu.my \\ ${ }^{2}$ Automotive Engineering Centre, Universiti Malaysia Pahang, \\ 26600 Pekan, Pahang, Malaysia \\ Email: mustafizur@ump.edu.my
}

\begin{abstract}
In this work, the numerical simulation of steady heat transfer and fluid flow over a bank of flat tubes in staggered configurations for determining the constant surface temperature is presented. The results are attained using the finite volume method (FVM) and body fitted coordinates (BFC) technique. Transverse ratios $\left(\mathrm{S}_{\mathrm{T}} / \mathrm{D}_{\mathrm{s}}\right)$ of the pitch to small diameter of 3.0, 4.0 and 6.0 are also considered. The Reynolds numbers used are 10, 20, 60, 80 and 100, and the Prandtl number is taken as 0.7. The isothermal line, streamline and average Nusselt number were analyzed in this paper. It was found that the strength of the heat transfer between the surface of the tubes and the air flow increases with increasing Reynolds number and increasing pitch-to-diameter ratios. Also, the effect of the Reynolds number clear for the isothermal line, streamline and the average Nusselt number.
\end{abstract}

Keywords: Forced convection; flat tube; staggered arrangement; finite volume method; body fitted coordinate.

\section{INTRODUCTION}

The flow of fluids and heat transfer in tube banks represents an idealization of many industrially-important processes. Tube bundles are widely employed in cross-flow heat exchangers, the design of which is still based on empirical correlations of heat transfer and pressure drops. Heat exchangers with tube banks in the cross-flow are of great practical interest in many thermal and chemical engineering processes (Buyruk, 2002; Incropera and Dewitt, 1996; Kaptan, Buyruk and Ecder, 2008; Liang and Papadakis, 2007; Mandhani, Chhabra and Eswaran, 2002; Wang, Penner and Ormiston, 2000). Flat tubes, however, have not been investigated to the same extent, notwithstanding the fact that they play an important role in many technical applications, such as in modern heat exchangers and automotive radiators. Flat tube designs have recently been introduced for use in automotive air conditioning evaporators and condensers. Recent developments in automotive brazed aluminum manufacturing technology have made the cost of flat tube heat exchangers construction more favorable (Webb, 1993). Flat tube heat exchangers are expected to have better air-side heat transfer coefficients and a lower air-side pressure drop compared to circular tube heat exchangers. The pressure drop is expected to be lower than that of circular tubes due to the smaller wake area. For 
the same reason, vibration and noise are expected to be less pronounced in flat tube heat exchangers compared to circular tube heat exchangers. Reports on air flow over a bank of flat tubes are limited, except for the recent study by Bahaidarah, Anand and Chen (2005) in which two-dimensional numerical, steady, laminar, incompressible flow over a bank of flat tubes are researched for both in-line and staggered configurations.

Two-dimensional numerical simulations of heat transfer and fluid flow over a bank of flat tubes have been considered for both in-line and staggered configurations. As for the two types of boundary condition, isothermal and isoflux, the effects of the Reynolds number, Prandtl number, height ratio and length ratio on the Nusselt number, and explains the dimensionless pressure drop. Relationships with low pressure are suggested on Nusselt number and optimum configurations have been determined (Benarji, Balaji and Venkateshan, 2008). Jue, Wu and Huang (2001) studied fluid flow and heat transfer across three heated cylinders arranged in the form of an isosceles triangle between two parallel plates. The continuity, momentum and energy equations were solved using the finite element method. The average change in the drag coefficient, the time mean Nusselt number around the surface of the three cylinders and the surface of the mean value of time, and the mean Nusselt number have been investigated in each cylinder. The calculation was carried out for: $100 \leq \operatorname{Re} \leq 300$ and $0.5 \leq$ gap/diameter $\leq 1.25$. A two-dimensional, laminar and steady flow numerical study comparing the performance of flat and oval tubes to that of the round tube heat exchanger was carried out, in the case of the simulation of specific heat flow along the tube walls. Was the use of volume control finite element method in conjunction with the flow conditions imposed periodically fully developed to implement. The Reynolds number range in the study was 50 to 350 . Fluids of Prandtl number 0.7 and 7.0 were considered. For the planned cases, the percentage increase in heat transfer is less than one, indicating that the round tube excelled over both the flat tube and oval tube on the basis of heat transfer considerations alone (Fullerton and Anand, 2010).

A numerical and experimental study of the optimal geometric arrangement of staggered parallel plates in a fixed volume with forced convection heat transfer was conducted. In the first part of the study it is established experimentally that an optimal spacing exists between the two adjacent rows of plates. Experimental results are reported for air in the range $1000 \leq \operatorname{Re}_{\mathrm{L}} \leq 6000$, where $\mathrm{L}$ is the swept length of the fixed volume. In the second part of the study, numerical results support and extend these findings to $100 \leq \mathrm{Re}_{\mathrm{L}} \leq 10000$. In addition, association with optimal spacing and maximum heat transfer rate results set the basis for a theoretical method of intersecting asymptotes and two (small and large) spacings of the geometrical arrangement (Fowler et al., 1997). Study of heat transfer by convection in air-cooled condensers was carried out and the system improved. In order to enhance the performance of air-cooled condensers, it is important to take into account both the condensation inside the condenser tubes and convection outside, where the improvement on the convection side is dominant. Computational fluid dynamics software (CFD) is used to solve the problem. Theoretical results show that the angle of the proposed optimum conditions for the two cases is about 4 degrees, with the proportion of the opposite side being 0.58 . This leads to an improvement in the heat transfer coefficient by a factor (Kh) of 1.469 and 1.46 against an increase in pressure drop factor (KP) of 2.12 and 1.95 and one for the case of case two, respectively (Awad et al, 2007). This study used the finite volume method to solve the Navier-Stokes equations and energy conservation equation for the laminar two-dimensional flow of an incompressible fluid in cross-flow, over a two staggered flat tube arrangement with constant physical properties for different classes of 
fluid flow boundary conditions. It is assumed along the lines of symmetry in the longitudinal direction through the centers of the tubes in a transverse row and through the centers of the tubes in a contiguous transverse row. New results are presented for nominal pitch-to-diameter ratios of 3.0, 4.0 and 6.0. The detailed findings, which include the isothermal line, streamline and average Nusselt number, are presented for a Prandtl number of 0.7 at Reynolds numbers of 10, 20, 60, 80 and 100.

\section{MATHEMATICAL MODEL}

Equations are to be written for the conservation of mass, momentum and energy in two dimensions. Velocity uses the Cartesian components $\mathrm{U}$ and $\mathrm{V}$, and it is assumed that the flow is two-dimensional steady and laminar, and the fluid is incompressible with constant thermal and transport properties. The governing equations consist of the following four equations for the dependent variables U, V, P, and T (Bejan, 2004):

$$
\text { Continuity: } \quad \frac{\partial \mathrm{U}}{\partial \mathrm{X}}+\frac{\partial \mathrm{V}}{\partial \mathrm{Y}}=0
$$

Momentum (Navier-Stokes):

X-direction (u momentum)

$$
\left.\begin{array}{l}
\mathrm{U} \frac{\partial \mathrm{V}}{\partial \mathrm{X}}+\mathrm{V} \frac{\partial \mathrm{V}}{\partial \mathrm{Y}}=-\frac{\partial \mathrm{P}}{\partial \mathrm{X}}+\frac{1}{\operatorname{Re}_{\mathrm{ST}}}\left[\frac{\partial^{2} \mathrm{U}}{\partial \mathrm{X}^{2}}+\frac{\partial^{2} \mathrm{U}}{\partial \mathrm{Y}^{2}}\right] \\
\mathrm{U} \frac{\partial \mathrm{V}}{\partial \mathrm{X}}+\mathrm{V} \frac{\partial \mathrm{V}}{\partial \mathrm{Y}}=-\frac{\partial \mathrm{P}}{\partial \mathrm{X}}+\frac{1}{\operatorname{Re}_{\mathrm{ST}}}\left[\frac{\partial^{2} \mathrm{~V}}{\partial \mathrm{X}^{2}}+\frac{\partial^{2} \mathrm{~V}}{\partial \mathrm{Y}^{2}}\right]
\end{array}\right\}
$$

Y-direction (v momentum)

Energy:

$$
\mathrm{U} \frac{\partial \theta}{\partial \mathrm{X}}+\mathrm{V} \frac{\partial \theta}{\partial \mathrm{Y}}=\frac{1}{\operatorname{Pr}_{\mathrm{Re}}}\left[\frac{\partial^{2} \theta}{\partial \mathrm{X}^{2}}+\frac{\partial^{2} \theta}{\partial \mathrm{Y}^{2}}\right]
$$

The governing equations were transformed into dimensionless forms by incorporating the following non-dimensional variables.

$$
(X, Y)=\frac{(x, y)}{S_{T}}, \quad P=\frac{p}{\rho U_{\infty}^{2}},(U, V)=\frac{(u, v)}{U_{\infty}}, \quad \theta=\frac{T-T_{\infty}}{T_{w}-T_{\infty}}, \quad R_{S_{T}}=\frac{U_{\infty} S_{T} / 2}{v}, \quad \operatorname{Pr}=\frac{\mu C_{P}}{k}
$$

Table 1. Boundary conditions for $\mathrm{U}, \mathrm{V}$ and $\theta$

\begin{tabular}{llccc}
\hline & & $\mathbf{U}$ & $\mathbf{V}$ & $\theta$ \\
\hline (I) & Inlet $(\mathrm{x}=0)$ & 1 & 0 & 0 \\
$(\mathrm{E})$ & Exit & $\frac{\partial \mathrm{U}}{\partial \mathrm{X}}=0$ & 0 & 0 \\
(A) & Tube surface & 0 & 0 & 1 \\
(B) & Symmetry & $\frac{\partial \mathrm{U}}{\partial \mathrm{Y}}=0$ & 0 & $\frac{\partial \theta}{\partial \mathrm{Y}}=0$ \\
\hline
\end{tabular}

The physical system considered in the present study is displayed in Figure 1. The boundary conditions used for the solution domain are a uniform inlet velocity, fully developed outflow, and a combination of symmetry and no-slip tube surfaces on the 
bottom and top boundaries. The boundary conditions prescribed for $U, \mathrm{~V}$ and $\theta$ are summarized in Table 1.

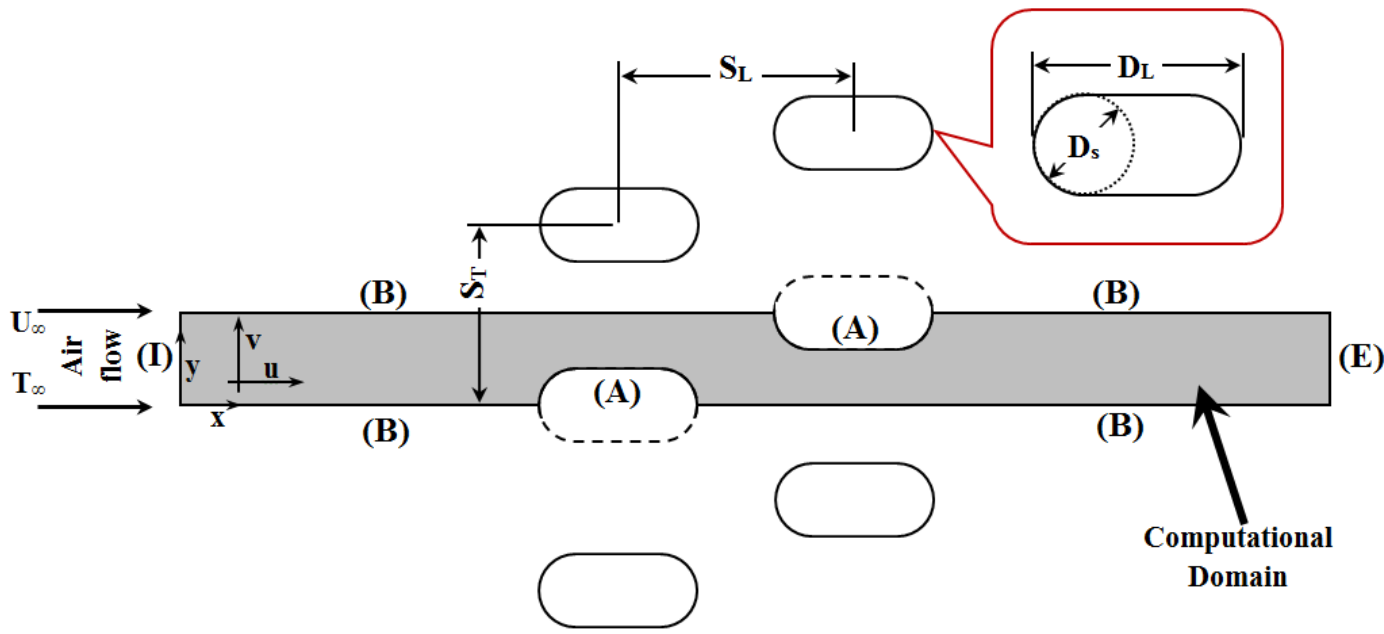

Figure 1. Staggered two flat tubes nomenclature: (a) tube arrangement; (b) solution domain.

The heat transfer coefficient $h$ can be expressed in dimensionless form by the local and average Nusselt numbers $N u$ and $\overline{N u}$, which are defined in Eq. (6a) and Eq. (7), respectively.

$$
\mathrm{Nu}_{\mathrm{x}}=\frac{\mathrm{h}_{\mathrm{x}} \mathrm{S}_{\mathrm{T}} / 2}{\mathrm{k}}=\frac{-\left(\frac{\partial \mathrm{T}}{\partial \mathrm{y}}\right) \frac{\mathrm{S}_{\mathrm{T}}}{2}}{\mathrm{~T}_{\mathrm{w}}-\mathrm{T}_{\mathrm{a}}}=-\frac{\partial \mathrm{T}^{*}}{\partial \mathrm{y}^{*}}
$$

To calculate the local Nusselt number, which indicates the superiority of convection heat transfer or conduction, we use the temperature gradient as follows:

$$
\begin{aligned}
& \mathrm{Nu}(i, j)=\frac{T(i, j+1)-T(i, j)}{y(i, j+1)-y(i, j)} \\
& \overline{N u}=\frac{1}{d A} \int N_{x} d A
\end{aligned}
$$

The set of conservation equations Eq. (3) and Eq. (4) can be written in general form in Cartesian coordinates as Eq. (8):

$$
\frac{\partial(\mathrm{U} \phi)}{\partial \mathrm{X}}+\frac{\partial(\mathrm{V} \phi)}{\partial \mathrm{Y}}=\frac{\partial}{\partial \mathrm{X}}\left(\Gamma \frac{\partial \phi}{\partial \mathrm{X}}\right)+\frac{\partial}{\partial \mathrm{Y}}\left(\Gamma \frac{\partial \phi}{\partial \mathrm{Y}}\right)+\mathrm{S}_{\phi}
$$

The continuity equation, Eq. (2), has no diffusion or source terms. It will be used to derive an equation for the pressure correction. The grid generation scheme based on elliptic partial differential equations is used in the present study to generate the curvilinear coordinates. Eq. (8) can be transformed from the physical domain to the computational domain according to the following transformation 
$\varsigma=\varsigma(x, y), \eta=\eta(x, y)$ (Thompson et al, 1985). The final form of the transformed equation can be written as Eq. (9):

$$
\frac{\partial}{\partial \zeta}\left(\phi \mathrm{G}_{1}\right)+\frac{\partial}{\partial \eta}\left(\phi \mathrm{G}_{2}\right)=\frac{\partial}{\partial \zeta}\left(\frac{\Gamma}{\mathrm{J}}\left(\alpha \frac{\partial \phi}{\partial \zeta}-\gamma \frac{\partial \phi}{\partial \eta}\right)\right)+\frac{\partial}{\partial \eta}\left(\frac{\Gamma}{\mathrm{J}}\left(\beta \frac{\partial \phi}{\partial \eta}-\gamma \frac{\partial \phi}{\partial \zeta}\right)\right)+\mathrm{JS}_{\phi}
$$

They are expressed as:

$$
\left.\begin{array}{l}
\mathrm{G}_{1}=\mathrm{U} \frac{\partial \mathrm{Y}}{\partial \eta}-\mathrm{V} \frac{\partial \mathrm{X}}{\partial \eta}, \quad \mathrm{G}_{2}=\mathrm{V} \frac{\partial \mathrm{X}}{\partial \varsigma}-\mathrm{U} \frac{\partial \mathrm{Y}}{\partial \varsigma} \\
\mathrm{J}=\left(\frac{\partial \mathrm{X}}{\partial \varsigma} \frac{\partial \mathrm{Y}}{\partial \eta}-\frac{\partial \mathrm{Y}}{\partial \varsigma} \frac{\partial \mathrm{X}}{\partial \eta}\right), \quad \alpha=\left(\frac{\partial \mathrm{x}}{\partial \eta}\right)^{2}+\left(\frac{\partial \mathrm{y}}{\partial \eta}\right)^{2} \\
\gamma=\left(\frac{\partial \mathrm{x}}{\partial \varsigma} \frac{\partial \mathrm{x}}{\partial \eta}\right)+\left(\frac{\partial \mathrm{y}}{\partial \varsigma} \frac{\partial \mathrm{y}}{\partial \eta}\right), \quad \beta=\left(\frac{\partial \mathrm{x}}{\partial \varsigma}\right)^{2}+\left(\frac{\partial \mathrm{y}}{\partial \varsigma}\right)^{2}
\end{array}\right\}
$$

Eq. (9) was solved numerically using a control volume-based finite volume method. The solution was obtained by the marching type procedure, involving a series of two-dimensional elliptic problems in the cross-stream plane. The marching step size is $1 \times 10^{-4}$ along the axial distance. At each marching step, the strong coupling of pressure and velocity in the cross-section was calculated by the SIMPLE-algorithm on a collocated non-orthogonal grid. It is used to adjust the velocity field to satisfy the conservation of mass (Patankar, 1980). For the computational calculations, a computer code was prepared in FORTRAN-90. In the numerical calculation, the $662 \times 22$ grid arrangement is found to be sufficient for grid independent solutions, following which $2 D$-algebraic vectors were used.

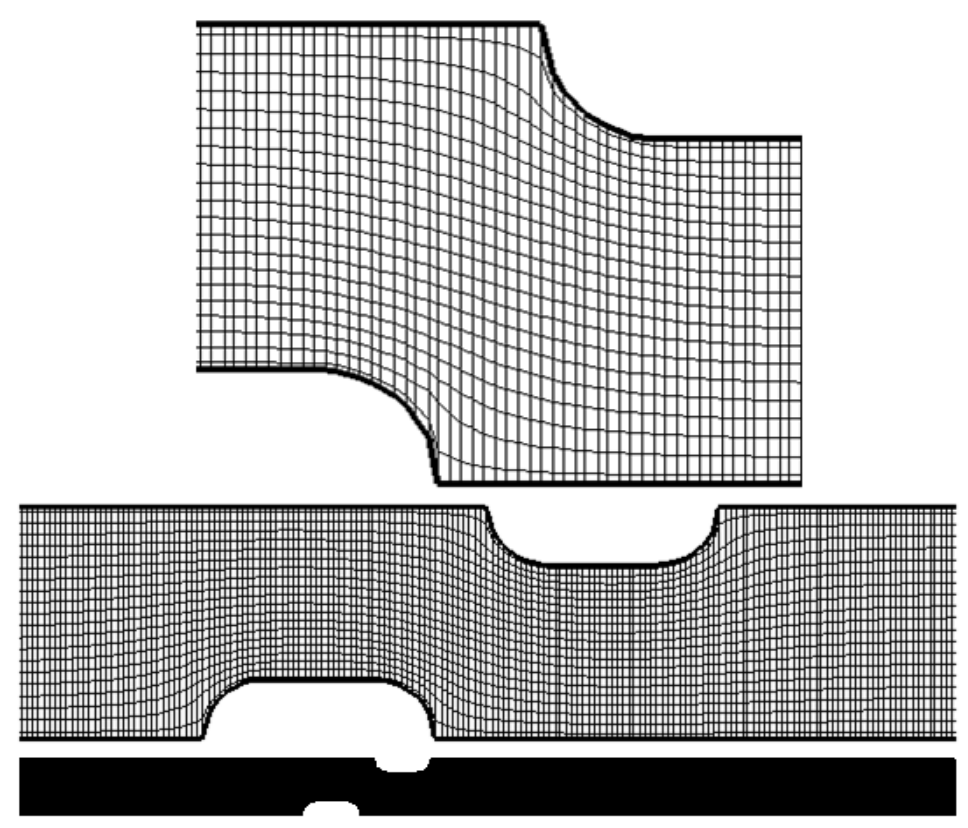

Figure 2. Schematic of grid systems generated from body fitted coordinates (BFC). 


\section{VALIDATION}

Bahaidarah, Anand and Chen (2005) conducted numerical simulations under steady state conditions for a bank of flat tubes. In order to validate with the same reference, a staggered configuration was used. Figure 3 shows a comparison between the present work and previous literature for the average Nusselt numbers against Reynolds numbers at $\operatorname{Pr}=0.7, \mathrm{~S}_{\mathrm{T}}=4.0$ and $\mathrm{S}_{\mathrm{L}}=6.0$. It can be seen that excellent agreement is achieved between the obtained results and the numerical results of Bahaidarah, Anand and Chen (2005).

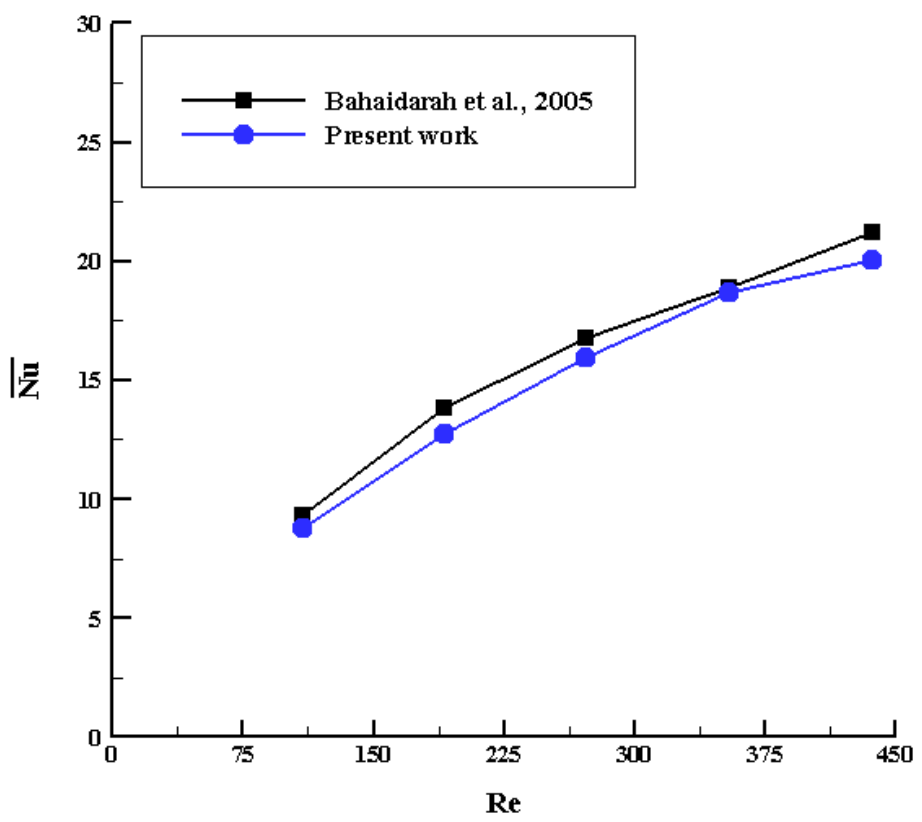

Figure 3. Comparison between the present study and previous literature (Bahaidrah et al, 2005) regarding average Nusselt numbers against Reynolds numbers at $\operatorname{Pr}=0.7$, transverse pitch $S_{T}=4.0$ and longitudinal pitch $S_{L}=6.0$.

\section{RESULTS AND DISCUSSION}

This section presents the numerical solutions of laminar forced convection heat transfer across two flat tubes with staggered arrays. The transverse pitch to small tube diameter ratios $\left(\mathrm{S}_{\mathrm{T}} / \mathrm{Ds}\right)$ of 3.0, 4.0 and 6.0 and the longitudinal $\mathrm{S}_{\mathrm{L}} / \mathrm{Ds}=3.0$ are constant. They are considered in the flow fields of $R e=10,20,60,80$ and 100. Regarding the normalized temperature (isotherms) all isotherms range from 0 to 1 , representing a low air temperature at the inlet increasing to a higher air temperature as it reaches the hot tube surface.

Figure 4 shows the effects of Reynolds numbers on the isotherms for the five modules for $S_{T} / D s=3.0$. A general view of the floods shows that as the value of the Reynolds number increases the lower value isotherms penetrate deeper, which means that cold air nears the hot surface. It is clear that the hot layer's thickness decreases with an increasing Reynolds number. All isothermal floods in Figures 5 and 6 show the effect of varying the transverse ratio $S_{T} / D s$ on the isotherms, at $S_{T} / D s=4.0$ and $S_{T} / D s=6.0$ respectively, at same the Reynolds numbers. 


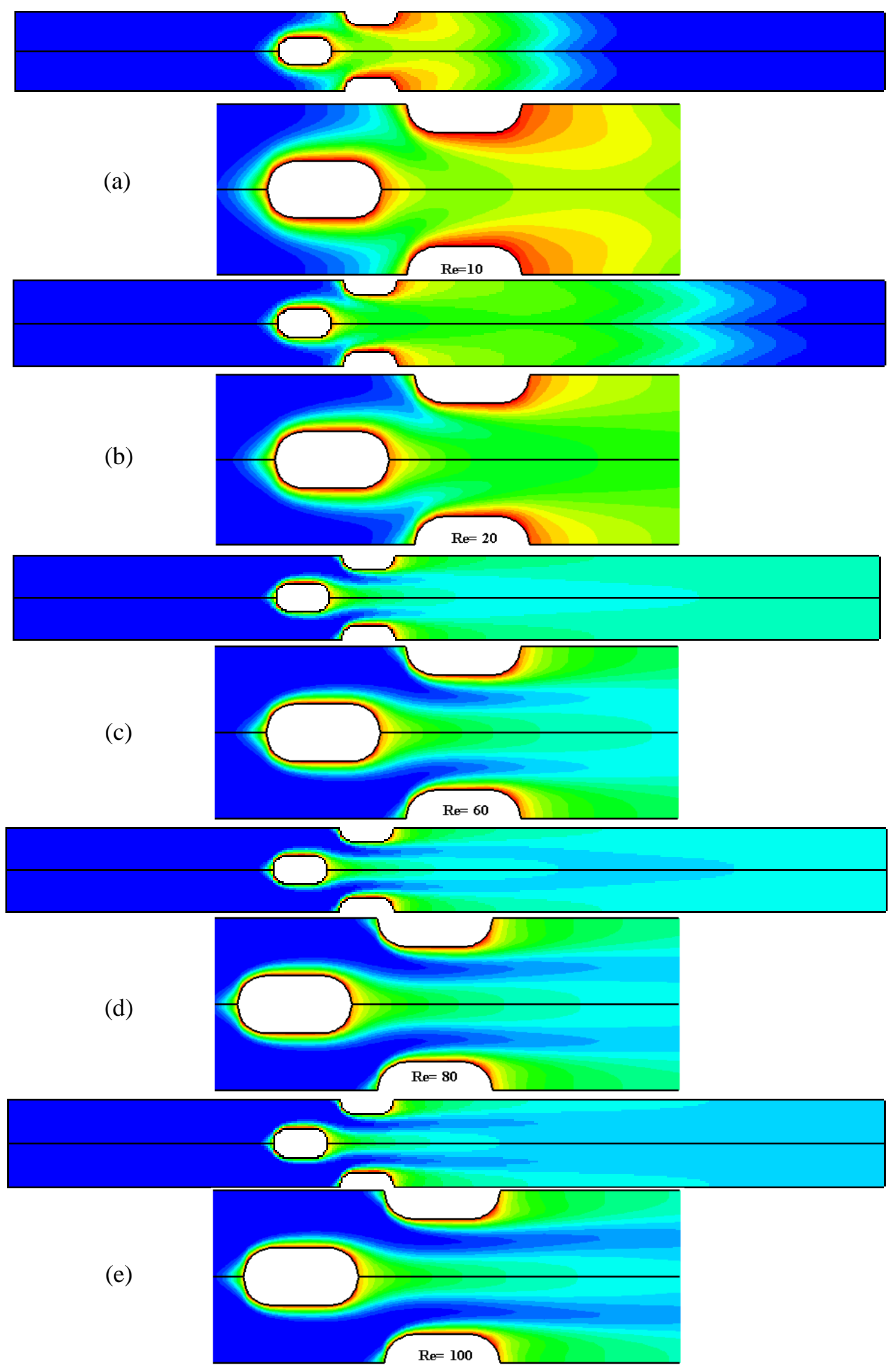

Figure 4. Effect of Reynolds number on isotherms for $\mathrm{S}_{\mathrm{T}} / \mathrm{Ds}=3.0$ and $\mathrm{S}_{\mathrm{L}} / \mathrm{Ds}=3.0$ : (a) $\operatorname{Re}=10$, (b) $\operatorname{Re}=20$, (c) $\operatorname{Re}=60$, (d) $\operatorname{Re}=80$, and (e) $\operatorname{Re}=100$. 


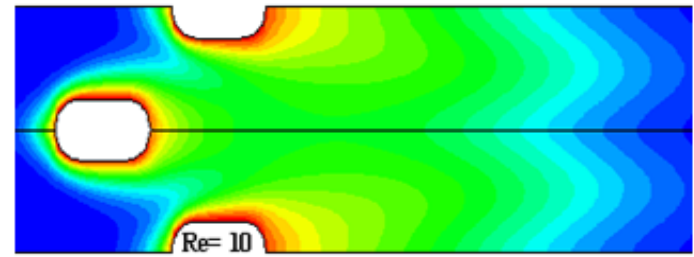

(a)

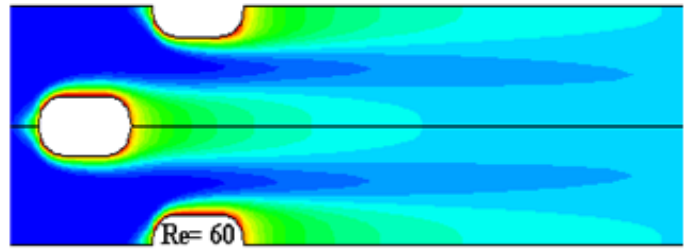

(c)

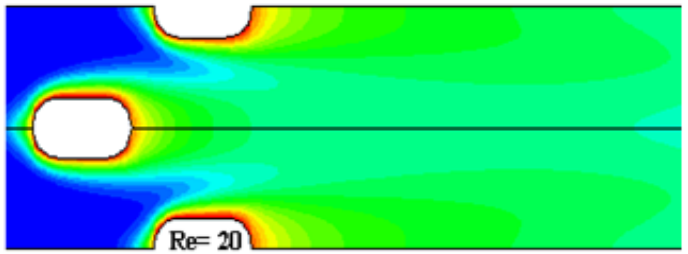

(b)

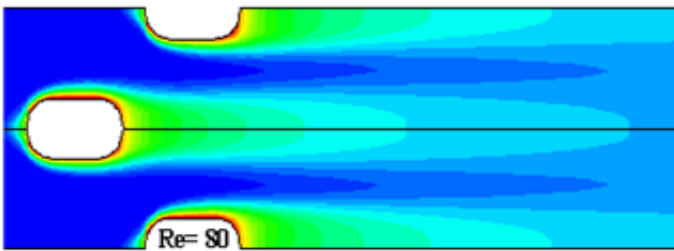

(d)

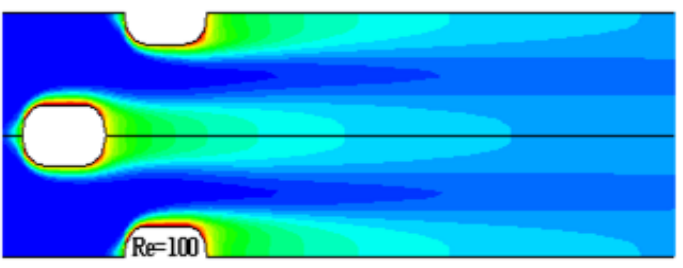

(e)

Figure 5. Effect of Reynolds number on isotherms for $\mathrm{S}_{\mathrm{T}} / \mathrm{Ds}=4.0$ and $\mathrm{S}_{\mathrm{L}} / \mathrm{Ds}=3.0$ :

(a) $\operatorname{Re}=10$, (b) $\operatorname{Re}=20$, (c) $\operatorname{Re}=60$, (d) $\operatorname{Re}=80$, and (e) $\operatorname{Re}=100$.

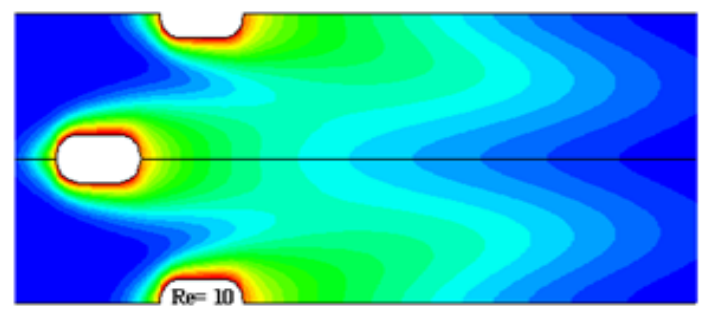

(a)

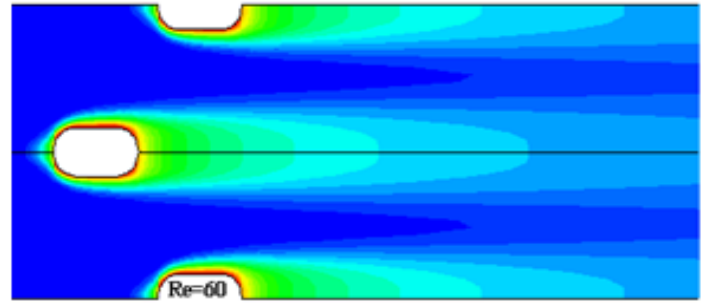

(c)

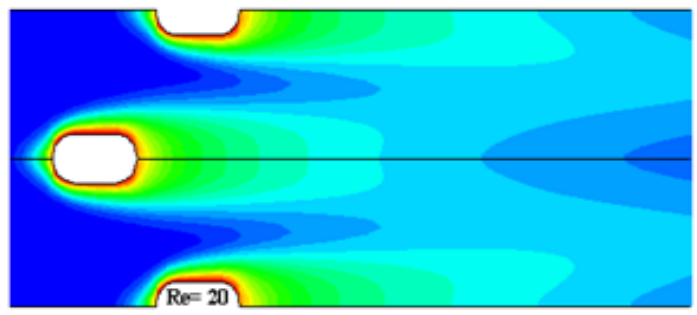

(b)

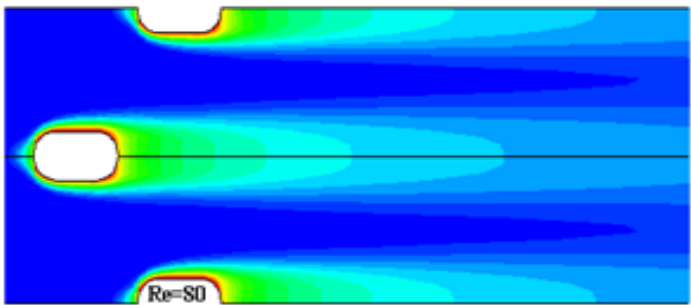

(d)

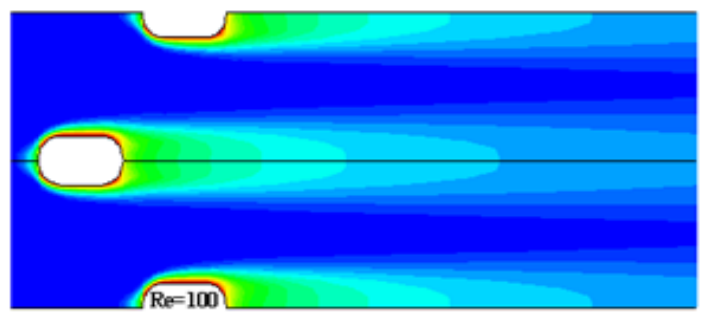

(e)

Figure 6. Effect of Reynolds number on isotherms for $\mathrm{S}_{\mathrm{T}} / \mathrm{Ds}=\mathrm{L} 2=6.0$ and $\mathrm{S}_{\mathrm{L}} / \mathrm{Ds}=3.0$ : (a) $\operatorname{Re}=10$, (b) $\operatorname{Re}=20$, (c) $\operatorname{Re}=60$, (d) $\operatorname{Re}=80$, and (e) $\operatorname{Re}=100$. 
Figures 7-9 presented streamlines at $S_{\mathrm{T}} / \mathrm{Ds}=3.0$ for $\mathrm{Re}=10,20,60,80$ and 100. It is interesting to note the difference between the flows over the front of the tube compared with the first tube for the next second tube. This can also be repeated as a symmetric flow pattern on the tubes to be considered in the following figure. In this case, there are very small flow recirculation regions behind the first tube. The same flow recirculation regions behind the second tube at a low velocity of air around $\operatorname{Re}=20$ can also be clearly seen. An increase in the flow recirculation region behind the second tube with increasing Reynolds number is noted, as well as the small effect of the flow recirculation region behind the first tube, and an increase with Reynolds number.

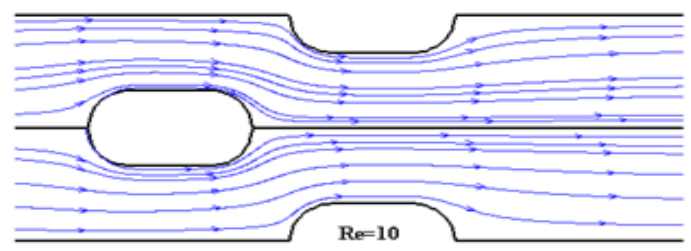

(a)

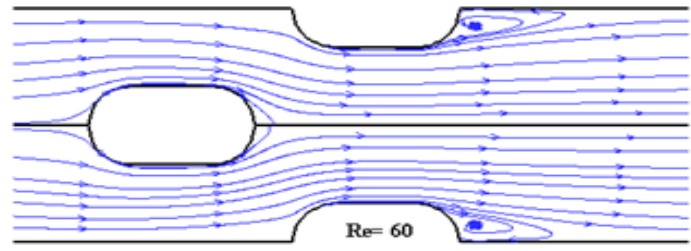

(c)

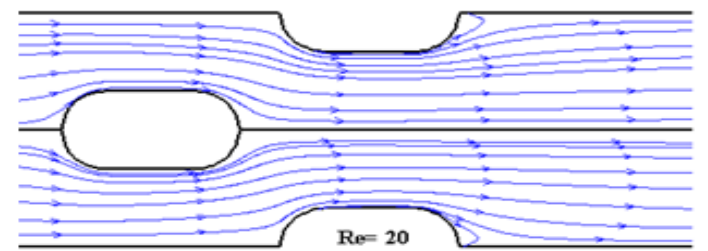

(b)

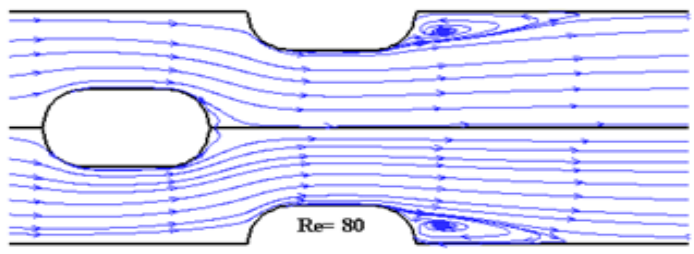

(d)

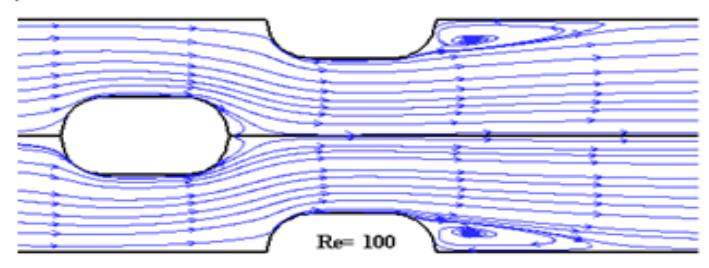

(e)

Figure 7. Effect of Reynolds number on the streamline for $\mathrm{S}_{\mathrm{T}} / \mathrm{Ds}=3.0$ and $\mathrm{S}_{\mathrm{L}} / \mathrm{Ds}=3.0$ : (a) $\operatorname{Re}=10$, (b) $\operatorname{Re}=20$, (c) $\operatorname{Re}=60$, (d) $\operatorname{Re}=80$, and (e) $\operatorname{Re}=100$.

Figure 10 shows the relation between average Nusselt numbers and Reynolds numbers of the first tube for three modules of the transverse pitch (ST/Ds=3.0, 4.0 and 6.0). It can be seen that the $\overline{N u}$ numbers increased with increasing Re numbers as well as the pitch-to-diameter ratio $\left(\mathrm{S}_{\mathrm{T}} / \mathrm{Ds}\right)$. However, further increase in the pitch-to-diameter ratio will also additionally improve the heat transfer. The average Nusselt numbers from the second tube at various Reynolds numbers are presented in Figure 11. The same profile can be seen as in the previous figure, and the average Nusselt numbers are lower compared to the first tube. 


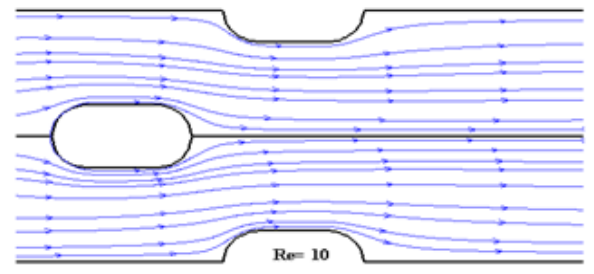

(a)

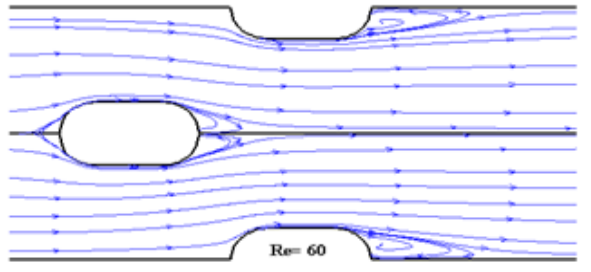

(c)

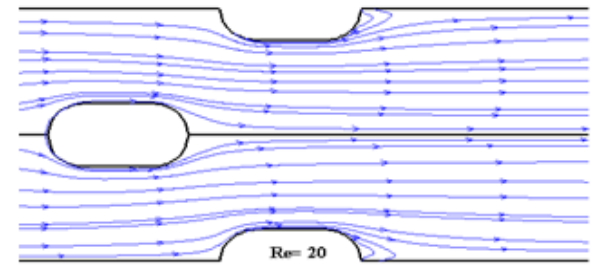

(b)

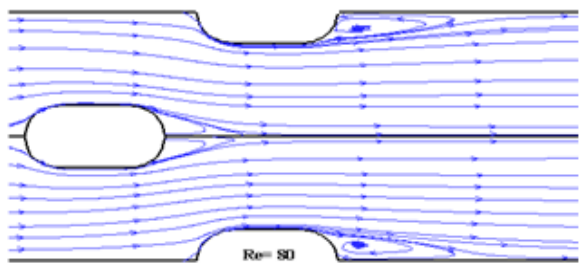

(d)

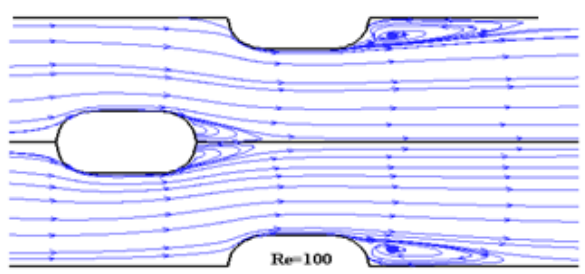

(e)

Figure 8. Effect of Reynolds number on the streamline for $\mathrm{S}_{\mathrm{T}} / \mathrm{Ds}=4.0$ and $\mathrm{S}_{\mathrm{L}} / \mathrm{Ds}=3.0$ : (a) $\operatorname{Re}=10$, (b) $\operatorname{Re}=20$, (c) $\operatorname{Re}=60$, (d) $\operatorname{Re}=80$, and (e) $\operatorname{Re}=100$.

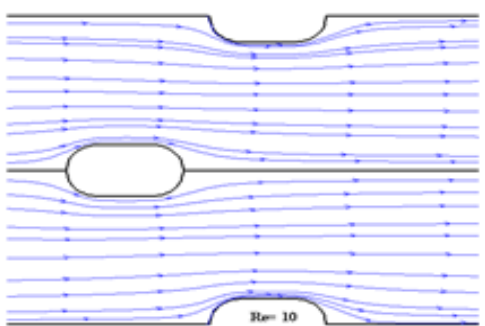

(a)

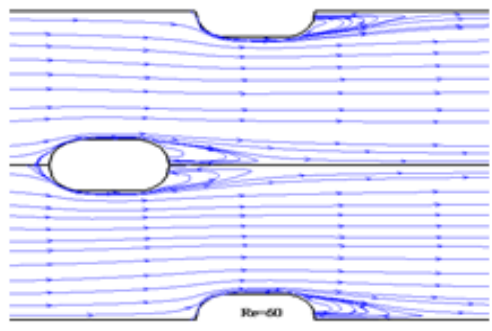

(c)

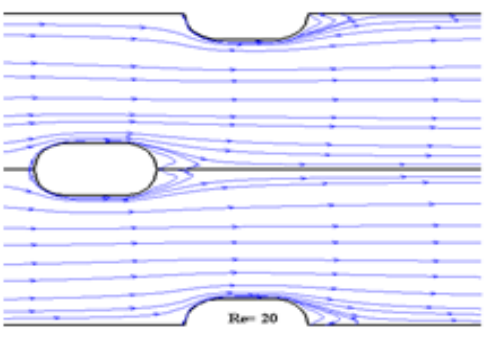

(b)

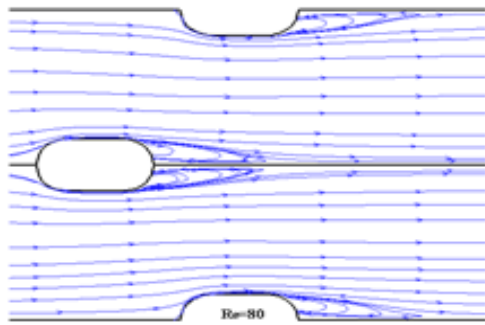

(d)

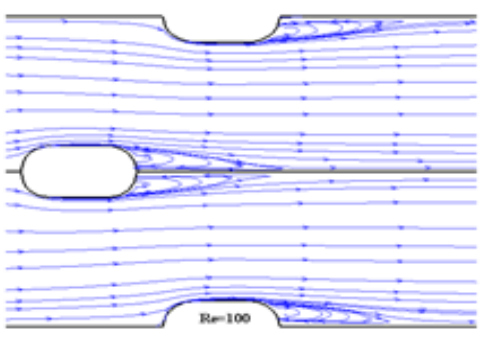

(e)

Figure 9. Effect of Reynolds number on the streamline for $\mathrm{S}_{\mathrm{T}} / \mathrm{Ds}=6.0$ and $\mathrm{S}_{\mathrm{L}} / \mathrm{Ds}=3.0$ : (a) $\operatorname{Re}=10$, (b) $\operatorname{Re}=20$, (c) $\operatorname{Re}=60$, (d) $\operatorname{Re}=80$, and (e) $\operatorname{Re}=100$. 


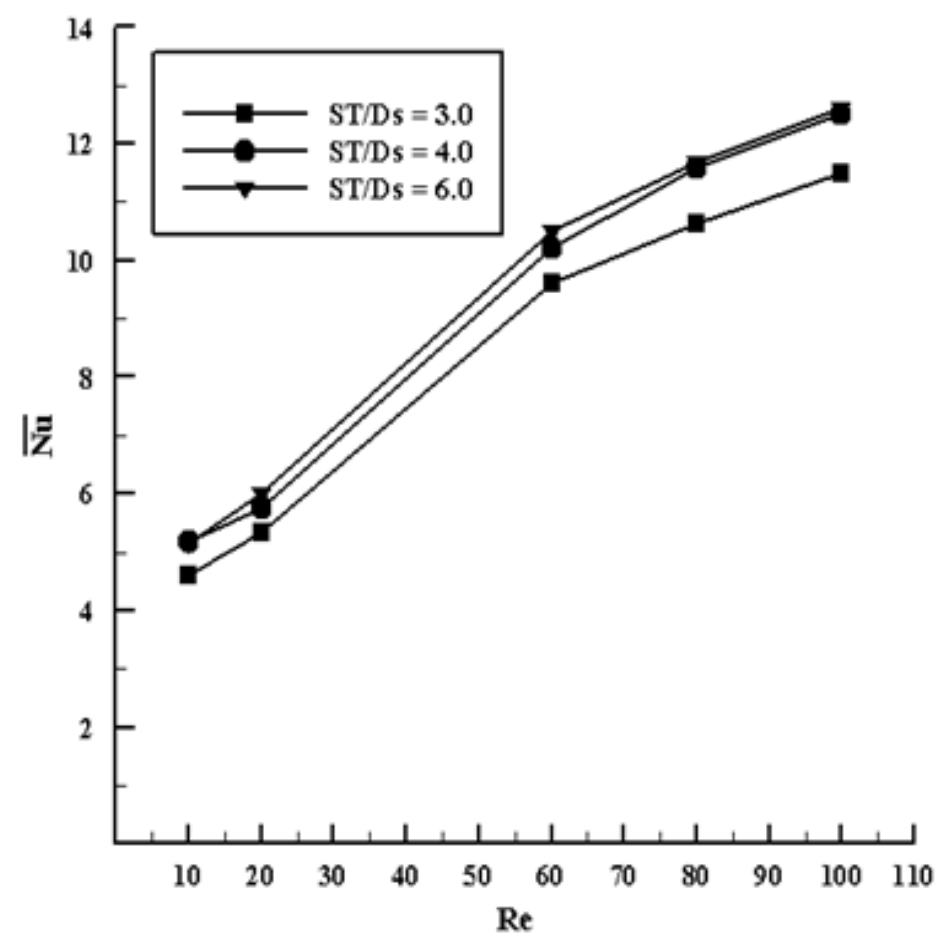

Figure 10. Effect of Reynolds numbers on average Nusselt numbers with different $\mathrm{S}_{\mathrm{T}} / \mathrm{Ds}$ for the first tube.

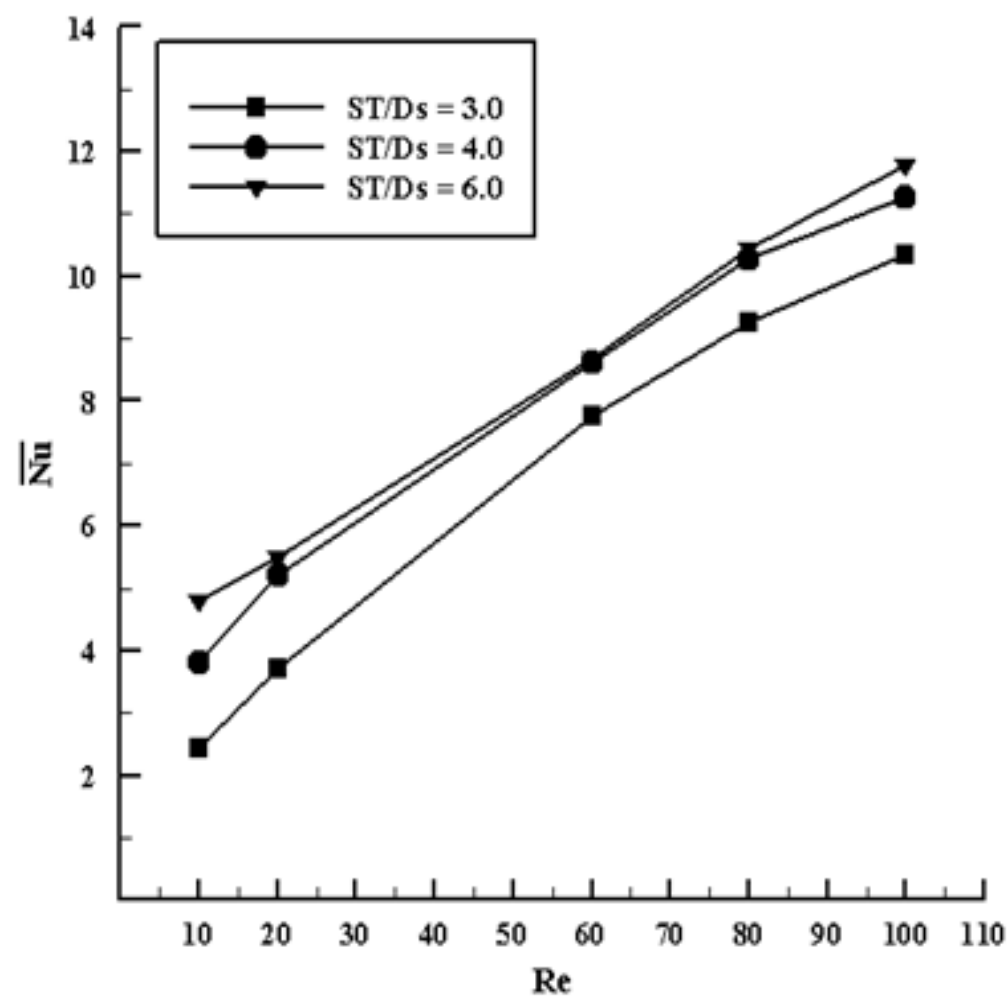

Figure 11. Effect of Reynolds numbers on average Nusselt numbers with different $\mathrm{S}_{\mathrm{T}} / \mathrm{Ds}$ for the second tube. 


\section{CONCLUSION}

A finite volume method with co-located variable storage on body fitted coordinates is used to predict the heat transfer and fluid flow over two staggered flat tubes and the temperature of the tube surface due to side heat transfer air flow. The numerical results of the temperature distributions, the streamline of the air flow and the average Nusselt number were studied. It is observed that:

i) Heat transfer in the first tube is always less than in the second tube.

ii) The isothermal floods decrease with increasing Reynolds number.

iii) The flow recirculation region increases with increasing Reynolds number.

iv) The average Nusselt number of the air flow increases with increasing Reynolds number.

v) Finally, as the transverse pitch is increased, the average Nusselt number increases for any Reynolds number.

\section{ACKNOWLEDGEMENTS}

The authors would like to thank the Faculty of Mechanical Engineering at the Universiti Malaysia Pahang (UMP) and Universiti Malaysia Pahang for financial support under RDU110332. The first author is grateful to the assistance of Dr. Ahmed W. Mustafa (Tikrit University, Iraq).

\section{REFERENCES}

Awad, M.M., Mostafa, H.M., Sultan, G.I. and Elbooz, A. 2007. Performance enhancement of air-cooled condensers. Acta Polytechnica Hungarica, 4: 125142.

Bahaidarah, H.M.S., Anand, N.K. and Chen, H.C. 2005. A numerical study of fluid flow and heat transfer over a bank of flat tubes. Numerical Heat Transfer, Part A, 48: 359-385.

Bejan, A. 2004 Convection heat transfer. New York, John Wiley and Sons.

Benarji, N., Balaji, C. and Venkateshan, S.P. 2008. Unsteady fluid flow and heat transfer over a bank of flat tubes. Heat and Mass Transfer, 44: 445-461.

Buyruk, E. 2002. Numerical study of heat transfer characteristics on tandem cylinders, Inline and ataggered tube banks in cross-flow of air. International Communications in Heat and Mass Transfer, 29: 355-366.

Fowler, A.J., Ledezma, G.A. and Bejan, A. 1997. Optimal geometric arrangement of staggered plates in forced convection. International Journal of Heat Mass Transfer, 40: 1795-1805.

Fullerton, T.L. and Anand, N.K. 2010. Periodically fully-developed flow and heat transfer over flat and oval tubes using a control volume finite-element method. Numerical Heat Transfer, Part A, 57: 642-665.

Jue, T.C., Wu, H.W. and Huang, S.Y. 2001. Heat transfer predictions around three heated cylinders between two parallel plates. Numerical Heat Transfer, Part A, 40: 715-733.

Kaptan, Y., Buyruk, E. and Ecder, A. 2008. Numerical investigation of fouling on cross-flow heat exchanger tubes with conjugated heat transfer approach. International Communications in Heat and Mass Transfer, 35: 1153-1158. 
Liang, C. and Papadakis, G. 2007. Large eddy simulation of cross-flow through a staggered tube bundle at subcritical Reynolds number. Journal of Fluids and Structures, 23: 1215-1230.

Mandhani, V.K., Chhabra, R.P. and Eswaran, V. 2002. Forced convection heat transfer in tube banks in cross flow. Chemical Engineering Science, 57: 379-391.

Patankar, S.V. 1980. Numerical heat transfer and fluid flow. Washington, DC: Hemisphere.

Thompson, J.R., Warsi, Z.U.A. and Martin, C.W. 1985. Numerical grid generation, foundations and applications. New York: North Holland.

Wang, Y.Q., Penner, L.A. and Ormiston, S.J. 2000. Analysis of laminar forced convection of air for crossflow in banks of staggered tubes. Numerical Heat Transfer, Part A, 38: 819-845.

Webb, R.L. 1993. Principles of enhanced heat transfer. New York: John Wiley.

\section{NOMENCLATURES}

\begin{tabular}{|c|c|c|c|}
\hline A & Surface area of tube $\left[\mathrm{m}^{2}\right]$ & $\mathrm{P}$ & Dimensionless pressure \\
\hline $\mathrm{C}_{\mathrm{P}}$ & Specific heat $\left[\mathrm{J}^{\mathrm{K}} \mathrm{g}^{-1} \mathrm{~K}^{-1}\right]$ & $\operatorname{Pr}$ & Prandtl number \\
\hline $\mathrm{D}$ & Diameter of flat tube $[\mathrm{m}]$ & \multicolumn{2}{|c|}{ Greek symbols } \\
\hline $\begin{array}{l}\text { G1 } \\
\text { G2 }\end{array}$ & Contravariant velocity components & $\alpha$ & Thermal diffusivity $\left[\mathrm{m}^{2} \cdot \mathrm{s}^{-1}\right]$ \\
\hline h & $\begin{array}{l}\text { Convection heat transfer } \\
\text { coefficient }\left[\mathrm{W} \cdot \mathrm{m}^{-2} \mathrm{~K}^{-1}\right]\end{array}$ & $\Gamma$ & Diffusion coefficient \\
\hline $\mathrm{k}$ & $\begin{array}{l}\text { Thermal conductivity of the air } \\
{\left[\mathrm{W} \cdot \mathrm{m}^{-1} \mathrm{~K}^{-1}\right]}\end{array}$ & $\theta$ & Dimensionless temperature \\
\hline $\operatorname{Re}_{S T}$ & Reynolds number & $\mu$ & Dynamic viscosity [N.s.m $\left.{ }^{-2}\right]$ \\
\hline $\mathrm{T}$ & Temperature $\left[{ }^{\circ} \mathrm{C}\right]$ & $v$ & Kinematic viscosity $\left[\mathrm{m}^{2} . \mathrm{s}\right]$ \\
\hline S & Source term & $\rho$ & Density $\left[\mathrm{kg} \cdot \mathrm{m}^{-3}\right]$ \\
\hline $\mathrm{S}_{\mathrm{L}}$ & $\begin{array}{l}\text { Longitudinal distance between two } \\
\text { consecutive tubes }[\mathrm{m}]\end{array}$ & $\varsigma, \eta$ & Curvilinear coordinates \\
\hline $\mathrm{S}_{\mathrm{T}}$ & $\begin{array}{l}\text { Transverse distance between two } \\
\text { consecutive tubes [m] }\end{array}$ & $\phi$ & General dependent variable \\
\hline $\mathrm{u}, \mathrm{v}$ & Velocity components $\left[\mathrm{m} \cdot \mathrm{s}^{-1}\right]$ & $\alpha, \beta, \gamma$ & The coefficients of transformation \\
\hline $\mathrm{U}, \mathrm{V}$ & Dimensionless velocity & \multicolumn{2}{|c|}{ Subscripts } \\
\hline $\mathrm{x}, \mathrm{y}$ & Cartesian coordinates $[\mathrm{m}]$ & $\mathrm{a}$ & Air flow \\
\hline $\mathrm{X}, \mathrm{Y}$ & Dimensionless Cartesian coord. & $\mathrm{L}$ & Large Diameter of flat tube $[\mathrm{m}]$ \\
\hline $\mathrm{J}$ & Jacobian of the transformation & $\mathrm{s}$ & Small Diameter of flat tube $[\mathrm{m}]$ \\
\hline$\frac{\mathrm{Nu}}{\mathrm{Nu}}$ & Local and average Nusselt number & $\mathrm{w}$ & Wall of tube \\
\hline $\mathrm{p}$ & Pressure $\left[\right.$ N.m $\left.{ }^{-2}\right]$ & $\begin{array}{l}\mathrm{x} \\
\infty\end{array}$ & $\begin{array}{l}\text { Local } \\
\text { Free stream }\end{array}$ \\
\hline
\end{tabular}

